\title{
Poor dietary diversity, wealth status and use of un-iodized salt are associated with goiter among school children: a cross-sectional study in Ethiopia
}

Zegeye Abebe ${ }^{1}$, Ejigu Gebeye ${ }^{2}$ and Amare Tariku ${ }^{3 *}$ (D)

\begin{abstract}
Background: Globally, more than two billion people are at risk of iodine deficiency disorders, 32\% of which are school children. lodine deficiency has been recognized as a severe public health concern in Ethiopia, however little is known about the problem. Therefore, this study aimed to assess the prevalence of goiter and associated factors among school children (6 to 12 years) in Dabat District, northwest Ethiopia.

Methods: A school-based cross-sectional study was conducted from February 21 to March 31, 2016. A total of 735 school children were included in the study. A stratified multistage sampling followed by systematic sampling technique was employed to select the study participants. Thyroid physical examination was done and classified according to the World Health Organization recommendations as grade 0 , grade 1, and grade 2 . The level of salt iodine content was determined using the rapid field test kit. The value 0 parts per million (PPM), $<15$ PPM and $\geq 15$ PPM with the corresponding color chart on the rapid test kit were used to classify the level of iodine in the sampled salt. A multivariable logistic regression analysis was employed to identify factors associated with goiter. Adjusted Odds Ratio (AOR) with a 95\% Confidence Interval (Cl) was calculated to show the strength of association. In multivariable analysis, variables with a $P$-value of $<0.05$ were considered statistically significant.
\end{abstract}

Results: In this community, the overall prevalence of goiter was 29.1\% [95\% Cl: 25.9, 32.6], in which about 22. 4 and $6.7 \%$ had goiter grade 1 and grade 2, respectively. The age of children ( $A O R=1.13 ; 95 \% \mathrm{Cl}: 1.01,1.26$ ), being housewife mother $(\mathrm{AOR}=1.49 ; 95 \% \mathrm{Cl}: 1.08,2.15)$, use of unprotected well water source for drinking $(A O R=6.25 ; 95 \% \mathrm{Cl}: 2.50,15.66)$, medium household wealth status ( $A O R=1.78 ; 95 \% \mathrm{Cl}: 1.18,2.92)$, use of inadequately iodized salt ( $\mathrm{AOR}=2.79 ; 95 \% \mathrm{Cl}: 1.86,4.19)$, poor dietary diversity score of the child $(\mathrm{AOR}=1.92$; $95 \% \mathrm{Cl}: 1.06,3.48)$ and medium maternal knowledge ( $\mathrm{AOR}=0.65 ; 95 \% \mathrm{Cl}: 0.42,0.94)$ were significantly associated with goiter.

Conclusions: The prevalence of goiter is higher in Dabat District, which confirmed a moderate public health problem. Therefore, regular monitoring of household salt iodine content, improving access to safe water, promoting the importance of diversified food for children is recommended to address the higher burden of iodine deficiency.

Keywords: School children, Goiter, Salt iodine content, Ethiopia

\footnotetext{
* Correspondence: amaretariku15@yahoo.com

${ }^{3}$ Department of Human Nutrition, Institute of Public Health, College of

Medicine and Health Sciences, University of Gondar, P.O. Box: 196, Gondar,

Ethiopia

Full list of author information is available at the end of the article
}

(c) The Author(s). 2017 Open Access This article is distributed under the terms of the Creative Commons Attribution 4.0 International License (http://creativecommons.org/licenses/by/4.0/, which permits unrestricted use, distribution, and reproduction in any medium, provided you give appropriate credit to the original author(s) and the source, provide a link to the Creative Commons license, and indicate if changes were made. The Creative Commons Public Domain Dedication waiver (http://creativecommons.org/publicdomain/zero/1.0/) applies to the data made available in this article, unless otherwise stated. 


\section{Background}

Iodine Deficiency (ID) is associated with a larger range of abnormalities which collectively named as 'Iodine Deficiency Disorders (IDDs)' reflecting thyroid dysfunction [1]. Particularly, goiter is used to describe an abnormal enlargement of thyroid gland mainly due to the adaptive response to low dietary iodine intake [2]. Due to their rapid growth and increased nutritional requirement, school children are considered as the most vulnerable segment of the community [3].

Globally, the total goiter rate is estimated to be $15.8 \%$ [4] and nearly two billion people are at risk of ID, while one-third lives in areas where natural sources of iodine is low [5]. Regarding the school children, about 32\% are suffering from ID and related consequences [6]. Furthermore, the highest prevalence of ID is documented in Africa (42\%) [1, 7]. Of the African countries, the largest burden is found in Ethiopia [8], according to which $39.9 \%$ of children are iodine deficient [9].

ID is found to severely impair the physical and mental development of children. The previous studies noted that iodine-deficient children perform poorly in school, suffered from the higher incidence of learning disabilities and lower intelligent quotient (IQ) $[5,10]$. Besides to this, ID negatively affects working capacity, quality of life and economic productivity of the community at large [11]. Moreover, fatigue, poorer weight gain, cold intolerance, constipation, cretinism, congenital anomalies and iodine-induced hyperthyroidism is reported among iodine-deficient children $[5,12]$.

In addition to depletion of the iodine content of soil, the risk of developing ID is associated socio-demographic characteristics. Accordingly, age and sex of the child [13-15], larg famies [13], poor economic status [14], low maternal and paternal educational status [16-18], poor maternal knowledge about iodized salt $[6,16]$ and place of residence $[19,20]$ are significantly associated with ID. Furthermore, adding salt during food preparation [17], use of unpacked salt [21], storing salt for a longer duration, near to the fire, in open container, and exposing to heat and sunlight $[14,15]$ are found with increased odds of developing ID. Purchasing salt greater than $5 \mathrm{~kg}$ at once [14], consumption of food items containing goitrogens [15, 22, 23], and co-existing micronutrients deficiencies (iron, selenium and vitamin A deficiency) [24, 25] are also correlated with ID.

The government of Ethiopia has planned to achieve utilization of adequately iodized salt to at least $90 \%$ by the year 2015 [26]. Accordingly, the government designed National Nutrition Program, micronutrient guideline, and endorsed a proclamation for ensuring the availability of iodized salt. Moreover, Micronutrient Initiative (MI), Global Alliance for Improved Nutrition (GAIN), and United Nation Children's Fund (UNICEF) are some of the international partners working with Federal Ministry of Health to rectify the child undernutrition [26, 27]. However, only $23.3 \%$ of the households used adequately iodized salt and ID continues as a critical public health problem in Ethiopia [9, 27].

Moreover, because of their higher vulnerability, measuring ID among school children is deemed to reflect the iodine status of the entire population [2]. However, little is known about IDDs in the northern part of Ethiopia, even the previous limited studies were done before and immediately after the implementation of universal salt iodization [28]. Therefore, this study aimed to assess the prevalence of goiter and associated factors among school children in Dabat District, northwest Ethiopia.

\section{Methods}

Study setting

A school-based cross-sectional study was conducted from February 21 to March 31, 2016, in Dabat District, northwest Ethiopia. The district is found $821 \mathrm{~km}$ from Addis Ababa, the capital city of Ethiopia. The district has 26 rural and four urban Kebeles (smallest administrative unit in Ethiopia). The altitude of the district ranges from 1000 to $2500 \mathrm{~m}$ above the sea level. The total population of 175,737 lives in the district. Cereals, such as maize, sorghum, wheat, and barley are the main staple crops cultivated in the district. The district has six health centers and 31 health posts. There are 82 schools in the district, 79 of which are primary schools. The Health and Demographic Surveillance System (HDSS) site was also located in Dabat District. The HDSS site has been running since 1996 and hosted by the University of Gondar. The surveillance site covers thirteen kebeles (four urban and nine rural kebeles) selected by considering different ecological zones (high land, middle land and lowland).

\section{Sample size and sampling procedure}

All children aged 6-12 years who lived in HDSS site and attended primary school during the study period were eligible for the study. The sample size was calculated using Epi-info version 2.3 by using the following assumptions; the prevalence of goiter among school-aged children was $37.6 \%$ [28], 95\% level of confidence and 5\% margin of error. Finally, the sample size of 757 was obtained by considering $5 \%$ non-response rate and a design effect of 2. A multistage stratified sampling followed by systematic random sampling technique was employed to reach the study participants. Initially, schools were stratified into urban and rural. Of the total twenty-four primary schools in the HDSS site, five (one urban and four rural) schools with a total of 3429 students were selected using the lottery method. Number of students included in each school were proportionate-to-population size. 
Finally, a systematic sampling technique was employed to select the study subjects.

Physical examination was done for the selected child, after that using the child's name, parent's name and address, household visit was made by data collectors to gather the socio-demographic, the household utilization of iodized salt and dietary habit related characteristics of the child and the parents. Women who were majorly involved in food preparation of the household were selected as a respondent.

\section{Data collection instrument and procedure}

A structured interviewer-administered questionnaire was used to collect data. The questionnaire was first prepared in English and was translated into the local language (Amharic) and back translated to English to maintain consistency by two BSc holder English teachers who are also native speakers of Amharic language. Pretest was done on five percent of the sample out of the study area. Two days training on techniques of interview, salt iodine content determination and thyroid physical examinationwas given for data collectors and supervisors. A total of nine data collectors (two health officers, an environmental health professional, and six permanent data collectors of the HDSS site) and three supervisors (two public health experts and a medical doctor) were involved in the study. Accordingly, the thyroid physical examination was undertaken by two Health Officers under the supervision of a medical doctor. Determination of salt iodine content was done by the trained environmental health professional. Daily supervision and feedback were carried out by the investigators and supervisors during the entire data collection period.

\section{Assessment of goiter and salt iodine content}

The presence of goiter was assessed by the trained Health Officers with strict adherence to the standard procedures stipulated by the World Health Organization. Accordingly, goiter was defined as grade $\mathbf{0}$ if no palpable mass in the neck was detected, grade $\mathbf{1}$ if there was a mass in the neck consistent with palpable enlarged thyroid, but not visible when the neck was in the normal position, whereas grade 2 was a swelling in the neck that was visible when the neck is in a normal position and is consistent with an enlarged thyroid when the neck is palpated (palpable and visible). Lastly, the child was deemed as having goiter when he/she had goiter of grade 1 or 2 [29].

A tablespoon of salt was collected from each household and the MBI international Rapid Test Kit (RTK) was used to determine the level of salt iodine content $[16,27,29]$. The small cup in the kit was filled with salt and made the cup surface flat. Two drops of test solution from white ampule were added to the surface of the salt by piercing the white ampoule with a pin and gently squeezing the ampule. The salt iodine content was determined within one minute by comparing the color developed on the salt with the color chart. The value 0 Parts per Million (PPM), $<15$ PPM and $\geq 15$ PPM with the corresponding color chart on the rapid test kit were used to classify the level of iodine in the sampled salt. If no color appears, after $1 \mathrm{~min}$, five drops of the recheck solution from red ampule was added to a fresh salt sample and followed by two drops of test solution on the same salt sample. Then, a comparison was done with the color chart indicators for salt iodine content [29].

\section{Assessment of dietary diversity}

Determination of dietary diversity score (DDS) of the child was started by asking the mother to list all food consumed by the child in the previous $24 \mathrm{~h}$ preceding the survey. Then reported food items were classified into nine food groups, as starchy staples; dark green leafy vegetables; vitamin A rich fruits and vegetables; other fruits and vegetables; organ meat; flesh meat and fish; and egg [30]. Considering four food groups as the minimum acceptable dietary diversity, a child with a DDS of less than four was classified as having poor dietary diversity; otherwise, it was deemed to have good dietary diversity [30].

\section{Assessment of household wealth status and maternal knowledge}

Household's wealth index, adopted from EDHS 2011 [31], was determined using Principal Component Analysis (PCA) by considering the household assets, such as quantity of cereal products, type of house, livestock and agricultural land ownership. First, variables were coded between 0 and 1 . Then variables entered and analyzed using PCA, and those variables having a communality value of greater than 0.5 were used to produce factor scores. Finally, the factor scores were summed and ranked into tertiles as poor, medium and rich.

Similarly, the knowledge of mothers towards iodized salt use was computed by using nine knowledge item questions, adopted by reviewing different literatures $[7,16,28]$, including the health benefit of iodized salt, disorders resulted from ID, food sources of iodine, appropriate place for salt storage, time to add salt during food preparation, salt storage material and existence of law prohibiting selling of non-iodized salt in Ethiopia. Accordingly, the factor scores were summed and ranked into poor, medium and high.

\section{Data analysis}

The collected data were checked and entered into Epiinfo version 7 and exported to SPSS version 20 statistical software for analysis. Descriptive statics were carried out and the result was presented using text, tables and 
Table 1 Socio-demographic and economic characteristics of children and their parents, Dabat District, northwest Ethiopia $2016(n=735)$

\begin{tabular}{lll}
\hline Variables & Frequency & Percentage \\
\hline Sex of the child & 337 & \\
Male & 398 & 45.9 \\
Female & & 54.1 \\
Residence & 155 & \\
Urban & 580 & 21.1 \\
Rural & & 78.9
\end{tabular}

Mother's marital status

Currently married

Currently unmarried ${ }^{b}$

Religion

Orthodox

Muslim

Mother's education

Illiterate

Primary

Secondary and above

Father's education

|lliterate

Primary

Secondary and above

Mother's occupation

Housewife

Outdoor workers

Father's Occupation

Farmer
Merchant
Government employee
Others
amily size
$<6$
$\geq 6$

Family history of goiter

Yes

No

Source of drinking water

Tap
Protected well
Unprotected well
Protected spring
Unprotected spring
Water treatment habit
Yes

Yes
Table 1 Socio-demographic and economic characteristics of children and their parents, Dabat District, northwest Ethiopia $2016(n=735)$ (Continued)

\begin{tabular}{lll}
\hline No & 703 & 96.6 \\
Wealth status & & \\
Poor & 253 & 34.4 \\
Medium & 237 & 32.2 \\
Rich & 245 & 33.3 \\
\hline
\end{tabular}

${ }^{a}$ Daily laborer, student, pensioner

bWidowed, separated and single

graph. A binary logistic regression model was fitted to identify factors associated with goiter. Variables with a $p$-value less than $<0.2$ in the bivariable analysis and those which frequently showed significant association with goiter in the previous studies were fitted into the multivariable logistic regression analysis and backward LR method was employed. Both Crude Odds Ratio (COR) and Adjusted Odds Ratio (AOR) with the corresponding 95\% Confidence Interval (CI) were calculated to show the strength of association. In multivariable analysis, variables with a $p$-value of $<0.05$ were considered as statistically significant.

\section{Results}

Socio-demographic and economic characteristics

A total of 735 school children were included in the study, which makes a response rate of $97.1 \%$. The median age of children was 10 years with Inter-quartile Range (IQR) of 3 years. About 54.1 and $61.6 \%$ children were females and lived in a family size of greater than five, respectively. Three-quarters of mothers were illiterate and $56.5 \%$ were outdoor workers. Most (80.7\%) of the fathers were farmers (Table 1).

\section{Utilization of iodized salt and consumption of iodine-rich food}

A substantial proportion, (96.2\%), of households used unpacked salt for food preparation, and about $49.8 \%$ households' added salt at the beginning and middle of food preparation. Only one-third, (32.5\%), of the households used adequately iodized salt (Table 2). Furthermore, about $85.2 \%$ of children had DDS of below four (mean \pm SD of DDS of the children was $2.8 \pm 0.67$ ); while none of them were included fish in their diet within 7 days prior to the date of survey (Table 3).

\section{Mother's knowledge and attitude towards iodized salt use} One-third (33.2 and 29.1\%, respectively) of the mothers had higher knowledge and favorable attitude towards iodized salt use. Regarding the cause of goiter, some of the mothers believed that it is due to contaminated 
Table 2 Household utilization of iodized salt and handling practices, Dabat District, northwest, Ethiopia, $2016(n=735)$

\begin{tabular}{|c|c|c|}
\hline Variables & Frequency & Percentage \\
\hline \multicolumn{3}{|l|}{ Type of salt } \\
\hline Packed & 28 & 3.8 \\
\hline Unpacked & 707 & 96.2 \\
\hline \multicolumn{3}{|l|}{ Addition of salt during food preparation } \\
\hline At the beginning and the middle & 366 & 49.8 \\
\hline At the end & 369 & 50.2 \\
\hline \multicolumn{3}{|l|}{ Salt exposure to sunlight } \\
\hline Yes & 36 & 4.9 \\
\hline No & 699 & 95.1 \\
\hline \multicolumn{3}{|l|}{ Washing of salt to remove impurities } \\
\hline Yes & 14 & 1.9 \\
\hline No & 721 & 98.1 \\
\hline \multicolumn{3}{|l|}{ Quantity of salt purchased commonly } \\
\hline Less than $1 \mathrm{~kg}$ & 84 & 11.4 \\
\hline $1 \mathrm{~kg}$ & 456 & 62.0 \\
\hline $2-5 \mathrm{~kg}$ & 161 & 21.9 \\
\hline$>5 \mathrm{~kg}$ & 34 & 4.6 \\
\hline \multicolumn{3}{|l|}{ Place of salt storage } \\
\hline Near to the fire & 72 & 9.8 \\
\hline Away from the fire & 663 & 90.2 \\
\hline \multicolumn{3}{|l|}{ Salt storage material } \\
\hline With closed container & 696 & 94.7 \\
\hline Without closed container & 39 & 5.3 \\
\hline \multicolumn{3}{|l|}{ Duration of household salt storage } \\
\hline $1-8$ weeks & 670 & 91.2 \\
\hline$\geq 9$ weeks & 65 & 8.8 \\
\hline \multicolumn{3}{|l|}{ Salt iodine content } \\
\hline 0 ppm & 21 & 2.9 \\
\hline $1-14$ ppm & 475 & 64.6 \\
\hline$\geq 15$ ppm & 239 & 32.5 \\
\hline
\end{tabular}

water (34.5\%), while 13.8 and $23.4 \%$ of them thought that it was because of genetic predisposition and drinking leftover water from a person who had a goiter, respectively. Only a quarter, (23.4\%), of mothers considered that regular consumption of iodized salt can prevent goiter (Table 4).

\section{Prevalence of goiter among school children}

The overall prevalence of goiter was found to be 29.1\% [95\% CI: 25.9, 32.6]; one-fifth had grade-one goiter, while $6.7 \%$ had a grade two goiter. Moreover, goiter was more common among females (31.4\%) than males (26.4\%) (Fig. 1).
Table 3 Consumption of iodine rich foods and goiterogenic substances among school-aged children, Dabat District, northwest, Ethiopia, $2016(n=735)$

\begin{tabular}{|c|c|c|}
\hline Variables & Frequency & Percentage \\
\hline \multicolumn{3}{|l|}{ Milk and milk product } \\
\hline Never & 622 & 84.6 \\
\hline Once and more per week & 113 & 15.4 \\
\hline \multicolumn{3}{|l|}{ Meat } \\
\hline Never & 600 & 81.6 \\
\hline Once and more per week & 135 & 18.4 \\
\hline \multicolumn{3}{|l|}{ Egg } \\
\hline Never & 667 & 90.7 \\
\hline Once and more per week & 68 & 9.3 \\
\hline \multicolumn{3}{|l|}{ Cabbage $^{\text {b }}$} \\
\hline Never & 658 & 89.5 \\
\hline Once and more per week & 77 & 10.5 \\
\hline \multicolumn{3}{|l|}{ Millet $^{\mathrm{b}}$} \\
\hline Never & 718 & 97.7 \\
\hline Once and more per week & 17 & 2.3 \\
\hline \multicolumn{3}{|l|}{ Cereals commonly consumed ${ }^{\mathrm{a}}$} \\
\hline Maize & 12 & 1.6 \\
\hline Teff & 560 & 76.2 \\
\hline Sorghum ${ }^{b}$ & 509 & 69.3 \\
\hline Wheat & 664 & 90.3 \\
\hline Millet ${ }^{\mathrm{b}}$ & 9 & 1.2 \\
\hline Barely & 517 & 70.3 \\
\hline \multicolumn{3}{|l|}{ DDS } \\
\hline$<4$ food groups & 626 & 85.2 \\
\hline$\geq 4$ food groups & 109 & 14.8 \\
\hline
\end{tabular}

${ }^{\text {aMultiple responses }}$

${ }^{\mathrm{b}}$ Food items considered as containing goiterogenic substances

\section{Factors associated with goiter}

Both bivariable and multivariable logistic regression analyses were done to see the effect of the selected characteristics on goiter. As it is presented in Table 5, child age, dietary diversity, residence, source of drinking water, mother's and father's education, father's occupation, wealth status, the level of salt iodine content, and consumption of cabbage were the factors showed significant association with goiter in the bivariable analysis.

Nevertheless, the result of multivariable logistic analysis revealed that child age, dietary diversity, maternal occupation, knowledge on the use of iodized salt, household wealth status, the level of salt iodine content, and source of drinking water were significantly and independently associated with goiter. Consequently, with a year increase in age, the odds of having goiter were increased by $12 \%(\mathrm{AOR}=1.12 ; 95 \% \mathrm{CI}: 1.01,1.26)$. The likelihood of developing a goiter was 1.48 times $(\mathrm{AOR}=$ 
Table 4 Mother's knowledge and attitude towards iodized salt use, Dabat District northwest Ethiopia, $2016(n=735)$

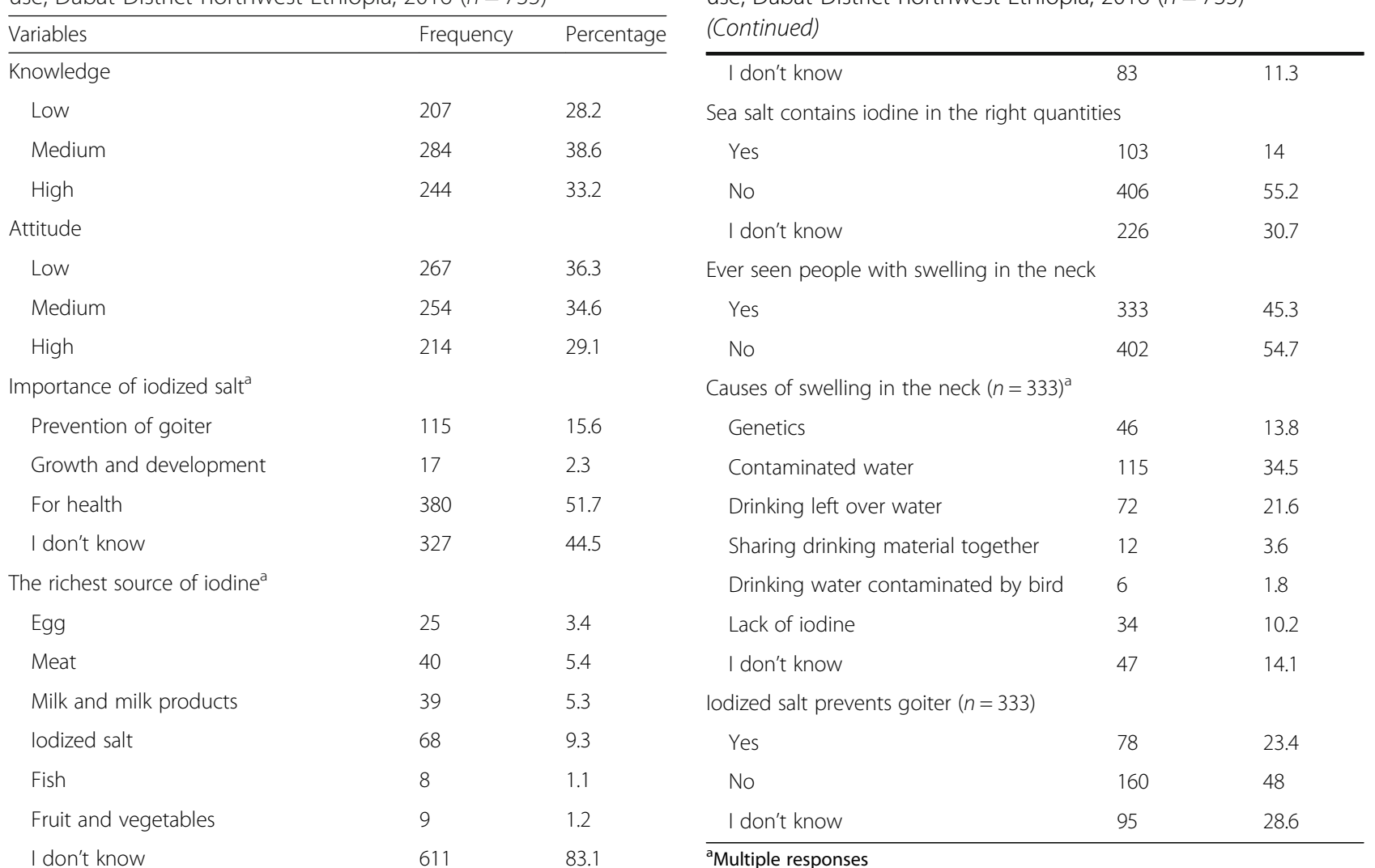

Disorders of lack of iodine ${ }^{a}$

$\begin{array}{lll}\text { Mental retardation } & 27 & 3.7\end{array}$

Goiter 182

Retarded growth 9

Abortion 9

Child mortality 2

I don't know 519

All salts contain iodine

$\begin{array}{lll}\text { Yes } & 77 & 10.5\end{array}$

No $\quad 220 \quad 29.9$

I don't know $\quad 438 \quad 59.6$

Selling of non-iodized salt is inhibited in Ethiopia

Yes 45

No 186

I don't know 504

Test of iodized salt is different from unionized one

Yes

No

185

I don't know

276

274

lodized salt has a harmful effect on health

Yes

33

619
Table 4 Mother's knowledge and attitude towards iodized salt Continued)

1.48; 95\% CI: 1.02, 2.14) higher among children whose mothers were housewives compared to children of mothers working outside the home.

In this study, the higher odds of developing a goiter were also observed among children living in the household using unprotected well water $(\mathrm{AOR}=6.38$; $95 \% \mathrm{CI}$ : $2.55,16.01)$ and with inadequately iodized salt (AOR $=$ 2.77; 95\% CI: 1.84, 4.15). As compared to the richer households, children from a household with medium wealth status were found at increased odds of having a goiter $(\mathrm{AOR}=1.75 ; 95 \% \mathrm{CI}: 1.07,2.87)$. Likewise, the odds of developing a goiter among children with poor DDS were 1.92 times (AOR $=1.92$; 95\% CI: $1.06,3.48$ ) higher compared to their counterparts. However, the odds of having goiter were decreased by $35 \%$ (AOR = 0.65; 95\% CI: $0.42,0.94$ ) among children whose mothers had medium knowledge towards iodized salt use as compared to children of mothers with poor knowledge (Table 5).

\section{Discussion}

According to the WHO/UNICEF/ICCIDD established criteria, the area is classified as endemic for ID when it has a total goiter rate of more than 5\% among school children (6-12 years). However, the public health importance of ID is defined as severe if the total goiter rate use, Dabat District northwest Ethiopia, 2016 ( $n=735)$ 


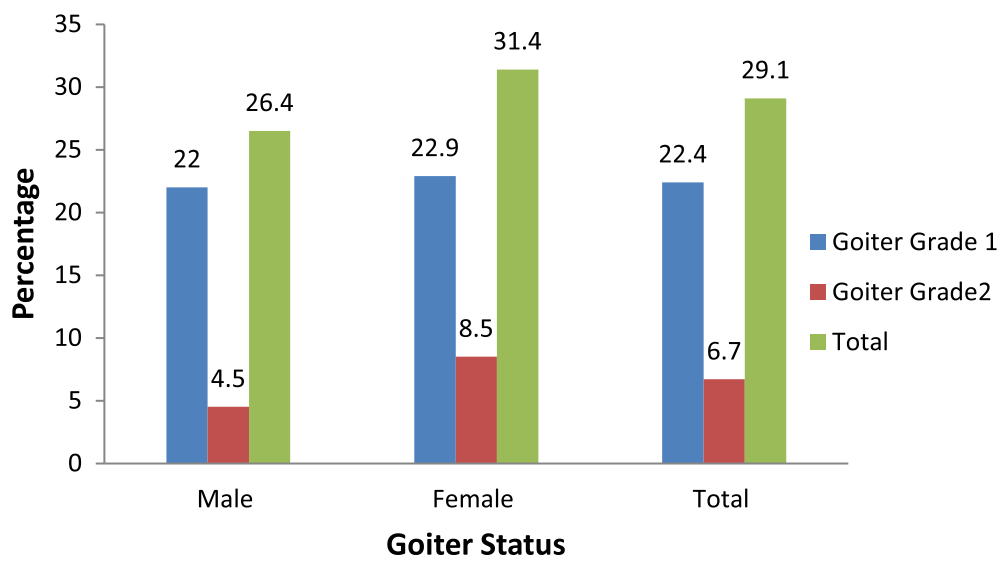

Fig. 1 Prevalence and severity of goiter by sex of the children, Dabat District, northwest Ethiopia, $2016(n=735)$

is greater than or equal to $30 \%$; otherwise, it is deemed to have moderate and mild public health significance, if the magnitude ranged from 20.0 to $29.9 \%$, and 5.0 $19.9 \%$, respectively [2].

Accordingly, the total goiter rate (29.1\%) of this study area suggests a moderate public health significance of ID. But, compared to other local studies, this finding was lower than the national average (39.9\%) [9] and what was reported from Lay-Armachiho District (37.6\%) [28] and Goba District (50.6\%) [13]. This is probably related to improvement in ensuring the availability of iodized salt throughout the country [27]. Currently, the government of Ethiopia gives priority to the implementation of mandatory salt iodization which is one of the proven strategies to address ID. For instance, China achieved a one-quarter $(25.2 \%)$ reduction in total goiter rate following the implementation of universal salt iodization [32].

However, this prevalence was highest compared to reports of other developing countries, such as India (4.8321.23\%) [33, 34], Nigeria (13.2\%) [35], and Saudi Arabia (11\%) [19]. The discrepancy could be attributed to shorter duration of time in the implementation of universal salt iodization program in the study area compared to the latter study settings. In fact, thyroid size is slow to respond to change in iodine status [36]. In Ethiopia, universal salt iodization program has been implemented since 2011, though only one-third (32.5\%) of the households utilize adequately iodized salt. As a result, the problem might still remain among children with larger thyroid size.

Similar to other reports elsewhere [13, 37], goiter was more prevalent among females in Dabat District. It is evident that females have a higher nutritional requirement for iodine, and reach to puberty earlier than males. In addition, it could be related to the effect of estrogen hormone on thyroid cell proliferation [38].
In this study, child age was independently associated with goiter. As the child's age advances by a year, the probability of developing goiter was increased by $12 \%$. The finding was supported by another study in Ethiopia [28] and Nigeria [35]. This is due to the fact that, iodine requirement increases with age. In addition, though dietary diversity is a proxy indicator of micronutrient adequacy of the diet [30], most of the children consumed undiversified diet in the study area.

The likelihood of developing goiter was 1.48 times higher among children whose mothers were housewives compared to children of the mothers working outside home. More than three quarters, $(77.5 \%)$, of the housewives in this study were illiterate. Illiterate mothers might have lesser capacity to understand the adverse consequences of ID and the food sources of iodine to appropriately feed their child. The previous reports also affirmed that undiversified diet and other poor feeding practices were commonly observed among children of illiterate mothers [31, 39].

In line with this fact, this study also showed increased odds of developing a goiter among children with poor DDS compared to their counterparts. In the case of the communities with cereal based monotonous dietary habit, most of the children suffered from ID and other co-existed micronutrient deficiencies, like vitamin $\mathrm{A}$ and iron deficiency [24, 40-42].

Household's source of drinking water was significantly associated with goiter. Accordingly, the higher odds of having goiter were noted among children from households using the unprotected source of water. The finding was in agreement with the previous studies of other developing countries $[10,43-45]$, in which contamination of drinking water with Coliforms and E. Coli contributes to the development of goiter. The current study revealed that the majority, (96.6\%), of the households did not treat water to make it safer for consumption. 
Table 5 Factors associated with goiter among school children, Dabat District, northwest Ethiopia, $2016(n=735)$

\begin{tabular}{|c|c|c|c|c|}
\hline \multirow[t]{2}{*}{ Variables } & \multicolumn{2}{|c|}{ Goiter status } & \multirow{2}{*}{$\begin{array}{l}\text { Crude odds } \\
\text { Ratio 95\% C1 }\end{array}$} & \multirow{2}{*}{$\begin{array}{l}\text { Adjusted odds } \\
\text { Ratio } 95 \% \mathrm{Cl}\end{array}$} \\
\hline & Yes \# & No \# & & \\
\hline Age & 214 & 521 & $1.13(1.02,1.26)$ & $1.12(1.01,1.26)$ \\
\hline \multicolumn{5}{|l|}{ Sex of the child } \\
\hline Male & 89 & 248 & 1.00 & * \\
\hline Female & 125 & 273 & $1.28(0.93,1.76)$ & * \\
\hline \multicolumn{5}{|l|}{ Residence } \\
\hline Urban & 29 & 126 & 1.00 & * \\
\hline Rural & 185 & 395 & $2.04(1.31,3.16)$ & * \\
\hline \multicolumn{5}{|l|}{ Mother's education } \\
\hline Illiterate & 179 & 382 & 1.00 & * \\
\hline Primary education & 19 & 81 & $0.50(0.29,0.85)$ & * \\
\hline Secondary and above & 16 & 58 & $0.59(0.33,1.05)$ & * \\
\hline \multicolumn{5}{|l|}{ Father's education } \\
\hline Illiterate & 127 & 278 & 1.00 & * \\
\hline Primary education & 71 & 167 & $0.93(0.66,1.32)$ & * \\
\hline Secondary and above & 16 & 76 & $0.46(0.26,0.82)$ & * \\
\hline \multicolumn{5}{|l|}{ Mother's occupation } \\
\hline House wife & 102 & 218 & $1.27(0.92,1.74)$ & $1.48(1.02,2.14)$ \\
\hline Outdoor workers & 112 & 303 & 1.00 & 1.00 \\
\hline \multicolumn{5}{|l|}{ Father's occupation } \\
\hline Farmer & 191 & 402 & 1.00 & * \\
\hline Merchant & 8 & 34 & $0.49(0.26,1.09)$ & * \\
\hline Government employee & 10 & 63 & $0.33(0.17,0.67)$ & * \\
\hline Others & 5 & 22 & $0.48(.18,1.28)$ & * \\
\hline \multicolumn{5}{|l|}{ Family size } \\
\hline$<6$ & 73 & 209 & 1.00 & * \\
\hline$\geq 6$ & 141 & 312 & $1.29(0.93,1.80)$ & * \\
\hline \multicolumn{5}{|l|}{ Family history } \\
\hline Yes & 17 & 39 & $1.07(0.59,1.93)$ & * \\
\hline No & 297 & 482 & 1.00 & * \\
\hline \multicolumn{5}{|l|}{ Source of drinking water } \\
\hline Tap water & 33 & 135 & 1.00 & 1.00 \\
\hline Protected well & 35 & 93 & $1.54(0.89,2.65)$ & $1.28(0.66,2.48)$ \\
\hline Unprotected well & 22 & 12 & $7.50(3.37,16.69)$ & $6.38(2.55,16.01)$ \\
\hline Protected spring & 79 & 192 & $1.68(1.06,2.67)$ & $1.14(0.64,2.03)$ \\
\hline Unprotected spring & 45 & 89 & $2.07(1.23,3.49)$ & $1.41(0.75,2.65)$ \\
\hline \multicolumn{5}{|l|}{ Household wealth index } \\
\hline Poor & 79 & 174 & $1.77(1.18,2.67)$ & $1.27(0.76,2.12)$ \\
\hline Medium & 85 & 152 & $2.18(1.45,3.28)$ & $1.75(1.07,2.87)$ \\
\hline Rich & 50 & 195 & 1.00 & 1.00 \\
\hline \multicolumn{5}{|l|}{ Type of salt } \\
\hline Packed & 7 & 21 & 1.00 & * \\
\hline Unpacked & 207 & 500 & $1.24(0.52,2.97)$ & * \\
\hline
\end{tabular}

Addition of salt during food preparation 
Table 5 Factors associated with goiter among school children, Dabat District, northwest Ethiopia, 2016 ( $n=735$ ) (Continued)

\begin{tabular}{|c|c|c|c|c|}
\hline At the beginning and the middle & 95 & 271 & $0.74(0.54,1.01)$ & * \\
\hline At the end & 119 & 250 & 1.00 & * \\
\hline \multicolumn{5}{|l|}{ Salt exposure to sunlight } \\
\hline Yes & 10 & 26 & $0.93(0.44,1.97)$ & * \\
\hline No & 204 & 495 & 1.00 & * \\
\hline \multicolumn{5}{|l|}{ Salt storage } \\
\hline Near to fire & 20 & 52 & $0.93(0.54,1.60)$ & * \\
\hline Away from fire & 194 & 469 & 1.00 & * \\
\hline \multicolumn{5}{|l|}{ Salt storage } \\
\hline With closed material & 203 & 493 & 1.00 & * \\
\hline Without closed material & 11 & 28 & $0.95(0.47,1.95)$ & * \\
\hline \multicolumn{5}{|l|}{ Duration of salt storage } \\
\hline $1-2$ months & 192 & 473 & 1.00 & * \\
\hline$>2$ months & 22 & 43 & $1.27(0.74,2.19)$ & * \\
\hline \multicolumn{5}{|l|}{ Salt iodine content } \\
\hline 0-14 ppm & 175 & 321 & $2.80(1.89,4.13)$ & $2.79(1.86,4.19)$ \\
\hline$\geq 15$ ppm & 39 & 200 & 1.00 & 1.00 \\
\hline \multicolumn{5}{|l|}{ Mother's knowledge } \\
\hline Poor & 69 & 138 & 1.00 & 1.00 \\
\hline Medium & 69 & 215 & $0.64(0.43,0.95)$ & $0.65(0.42,0.94)$ \\
\hline High & 76 & 168 & $0.90(0.61,1.35)$ & $0.99(0.64,1.55)$ \\
\hline \multicolumn{5}{|l|}{ Mother's attitude } \\
\hline Poor & 72 & 195 & $0.70(0.47,1.03)$ & * \\
\hline Medium & 68 & 186 & $0.69(0.47,1.03)$ & * \\
\hline High & 74 & 140 & 1.00 & * \\
\hline \multicolumn{5}{|l|}{ Cabbage consumption } \\
\hline Never & 200 & 460 & 1.00 & * \\
\hline Once and more per week & 14 & 61 & $0.53(0.29,0.97)$ & * \\
\hline \multicolumn{5}{|l|}{ DDS } \\
\hline$<4$ food groups & 196 & 430 & $2.30(1.35,3.93)$ & $1.92(1.06,3.48)$ \\
\hline$\geq 4$ food groups & 18 & 91 & 1.00 & 1.00 \\
\hline
\end{tabular}

*Not appeared in the final model (not significant) using backward LR method

In this study, household wealth status was inversely associated with risk of developing a goiter. The odds of developing goiter among children from households with medium wealth status were higher compared to children from richer households. The finding was in line with the studies done elsewhere [14, 40, 46]. Obviously, wealth status determines the household's food purchasing power and food security status [47]. Accordingly, rich households can access a variety of food which ultimately improves the child's dietary diversity. In addition, utilization of un-iodized salt is common among poor households [44].

It was documented that, poor maternal knowledge towards iodized salt use was positively associated with goiter [32, 40,45]. Similarly, the odds of having goiter were reduced by $35 \%$ among children whose mothers had medium knowledge compared to those children whose mothers had poor knowledge. Boosting mother's knowledge of iodized salt use is an important step to ensure appropriate utilization of iodized salt at the household level [48].

Finally, inadequate salt iodine content of the household was associated with the higher odds of developing a goiter. This finding was in line with another report from Ethiopia [28] and Saudi Arabia [19]. Implementation of universal salt iodization is the most cost effective and proven intervention to eliminate IDDs $[49,50]$, in spite of this fact only one-third of the households utilized adequately iodized salt and majority of children were found with poor dietary intake of iodine rich food. 
The study was conducted using relatively large sample size and in a well-defined population representing the northwest part of Ethiopia. In addition, the study also determined the recent iodized salt consumption. However, some of the limitations of this study should be taken into consideration. First, the study did not include biochemical markers of recent iodine status. Second, eventhough adequate training was given to field assistants (data collectors and supervisors) and mothers were clearly informed about the objectives of the study, still, there might be social desirability bias in responding type of salt use and handling practice.

\section{Conclusion}

The prevalence of goiter was higher in the study area which confirmed a moderate public health problem. Child age, dietary diversity score, maternal occupation, knowledge, the household source of drinking water, wealth status, and level of salt iodine content were significantly associated with goiter. Hence, regular monitoring of household salt iodine content, improving access to safe water and promoting dietary diversification is recommended to address the higher burden of ID. Finally, conducting further studies by including biochemical markers and determining salt iodine level using iodometric titration is recommended for the researchers.

\section{Abbreviations}

DDS: Dietary diversity score; EDHS: Ethiopia Demography and Health Survey; FAO: Food and Agricultural Organization; HDSS: Health and Demography Surveillance System; ICCIDD: International Committee of Control of lodine Deficiency Disorder; ID: Iodine Deficiency; IDD: Iodine Deficiency Disorder; PCA: Principal Component Analysis; PPM: Parts per Million; TGR: Total goiter rate; UNICEF: United Nation Children's Fund; WHO: World Health Organization

\section{Acknowledgements}

The authors would like to thank all respondents for their willingness to participate in the study. They are also grateful to North Gondar Zonal Health Department, Dabat District Health Office, and the University of Gondar for material support. Finally, the authors' appreciations go to Dabat HDSS site staffs for their unreserved contribution in data collection activities.

\section{Funding}

This study was funded by the Food and Nutrition Society of Ethiopia and the University of Gondar. The views presented in the article are of the author and not necessarily express the views of the funding organization. Food and Nutrition Society of Ethiopia and the University of Gondar were not involved in the design of the study, data collection, analysis, and interpretation.

\section{Availability of data and materials}

Data will be available upon request from the corresponding author.

\section{Authors' contributions}

ZA conceived the study, developed the tool, coordinated the data collection activity carried out the statistical analysis and drafted the manuscript. EG participated in the design of the study, tool development, and drafting the manuscript. AT participated in the design of the study and tool development, performed statistical analysis and drafted and critically reviewed the manuscript. All authors read and approved the final manuscript.

\section{Competing interests}

The authors declare that they have no competing interests.

\section{Consent for publication}

Not applicable.

\section{Ethics approval and consent to participate}

Ethical clearance was obtained from the Institutional Review Board of the University of Gondar (Ref. No. IPH/2885/2016). The supportive letter was obtained from North Gondar Zonal Health Department and Dabat District Health Office. Permission was obtained from each school director. During house to house data collection, written informed consent was obtained from each child family after briefly explaining the purpose, risk, and benefit of the study. All the procedure and purpose were told to the child, and assent was also obtained from each child before any data collection and physical examination. The child found to have goiter was linked to the nearest health institution. Health education about the use of iodized salt and handling practices in the household were given to each mother after data collection. Confidentiality of data was maintained by avoiding personal identifiers.

\section{Author details}

'Department of Public Health Officer, Institute of Public Health, College of Medicine and Health Sciences, University of Gondar, Gondar, Ethiopia. ${ }^{2}$ Department of Epidemiology and Biostatistics, Institute of Public Health, College of Medicine and Health Sciences, University of Gondar, Gondar, Ethiopia. ${ }^{3}$ Department of Human Nutrition, Institute of Public Health, College of Medicine and Health Sciences, University of Gondar, P.O. Box: 196, Gondar, Ethiopia.

Received: 5 July 2016 Accepted: 7 December 2016

Published online: 07 January 2017

\section{References}

1. Andersson M, Karumbunathan V, Zimmermann MB. Global iodine status in 2011 and trends over the past decade. J Nutr. 2012;142(4):744-50.

2. WHO. Urinary iodine concentrations for determining iodine status deficiency in populations. Vitamin and Mineral Nutrition Information System. Geneva: World Health Organization; 2013.

3. WHO. lodine status worldwide WHO Global Database on lodine Deficiency. In: de Benoist B, Andersson M, Egli I, Takkouche B, Allen H, editors. Geneva: World Health Organization; 2004.

4. Andersson M, Takkouche B, Egli I, Allen HE, Benoist B. Current global iodine status and progress over the last decade towards the elimination of iodine deficiency. Bull World Health Organ. 2005;83(7):518-25.

5. WHO. Guideline: fortification of food-grade salt with iodine for the prevention and control of iodine deficiency disorders. In. Geneva: World Health Organization; 2014.

6. Zimmermann MB, Andersson M. Update on iodine status worldwide. Curr Opin Endocrinol Diabetes Obes. 2012;19(5):382-7.

7. Buxton C, Baguune B. Knowledge and practices of people in Bia District, Ghana, with regard to iodine deficiency disorders and intake of iodized salt. Arch Public Health. 2012;70(5):5.

8. Andersson M, Zimmermann M. Global iodine nutrition: a remarkable leap forward in the past decade. IDD Newsletter. 2012;40(1):1-5.

9. Abuye C, Berhane Y, Akalu G, Getahun Z, Ersumo T. Prevalence of goiter in children 6 to 12 years of age in Ethiopia. Food Nutr Bull. 2007;28(4):391-8.

10. Wolka E, Shiferaw S, Biadgilign S. The effect of iodine-deficiency disorders on academic achievement of schoolchildren in Southern Ethiopia. Public Health Nutr. 2014;17(05):1120-4.

11. Win AZ. Micronutrient deficiencies in early childhood can lower a country's GDP: The Myanmar example. Nutrition. 2016;32(1):138-40.

12. WHO/FAO. Guidelines on food fortification with micronutrients. In. 2006.

13. Enyew HD, Zemedkun KG, Dagnaw AM. Prevalence of Goiter and Associated Factors Among Primary School Children Aged 6-12 Years Old in GobaTown, South East, Ethiopia. Int J Nutr Food Sc. 2015;4(3):381-7.

14. Matthys B, Davlatmamadova M, Karimova G, Jean-Richard V, Zimmermann $M B$, Wyss $K$. lodine nutritional status and risk factors for goitre among schoolchildren in South Tajikistan. BMC Endocr Disord. 2013;13(1):1.

15. Mezgebu Y, Mossie A, Rajesh PN, Beyene G. Prevalence and severity of iodine deficiency disorder among children 6-12 years of age in shebe senbo district, jimma zone, southwest Ethiopia. Ethiop J Health Sci. 2012; 22(3):196-204.

16. Gidey B, Alemu K, Atnafu A, Kifle M, Tefera Y, Sharma H. Availability of Adequate lodized Salt at Household Level and Associated Factors in Rural 
Communities in Laelay Maychew District, Northern Ethiopia: A Cross Sectional Study. J Nutr Health Sci. 2015;2(1):1.

17. Kazungu K, Mbakaya C, Makokha A. Factors contributing to iodide deficiency in coast province of Kenya. Eur J Res Med Sci. 2015;3(2). ISSN 2056-600X.

18. Kedir H, Berhane $Y$, Worku A. Subclinical lodine Deficiency among Pregnant Women in Haramaya District, Eastern Ethiopia. J Nutr Metab. 2014; 2014(2014). Article ID 878926.

19. Alsanosy RMA, Gaffar AM, Khalafalla HEE, Mahfouz MS, Zaid ANS, Bani IA. Current iodine nutrition status and progress toward elimination of iodine deficiency disorders in Jazan, Saudi Arabia. BMC Public Health. 2012;12(1):1.

20. Girma M, Loha E, Bogale A, Teyikie N, Abuye C, Stoecker BJ. lodine deficiency in primary school children and knowledge of iodine deficiency and iodized salt among caretakers in Hawassa Town: Southern Ethiopia. Ethiop J Health Dev. 2012;26(1):30-5.

21. Jaruratanasirikul S, Sangsupawanich P, Koranantakul O, Chanvitan P, Ruaengrairatanaroj $\mathrm{P}$, Sriplung $\mathrm{H}$. Maternal iodine status and neonatal thyroid-stimulating hormone concentrationa:community survey in Songkhla, southern Thailand. Public Health Nutr. 2009;12(12):2279-84.

22. Vanderpas J. Nutritional epidemiology and thyroid hormone metabolism. Annu Rev Nutr. 2006;26:293-322.

23. Simone AJ, Thamm M. lodine status in preschool children and evaluation of major dietary iodine sources. Eur J Nutr. 2013;52:1711-9.

24. Zimmermann MB. The influence of iron status on iodine utilization and thyroid function. Annu Rev Nutr. 2006;26:367-89.

25. Brauer VF, Schweizer U, Köhrle J, Paschke R. Selenium and goiter prevalence in borderline iodine sufficiency. Eur J Endocrinol. 2006;155(6):807-12.

26. Adish A, Chuko T, Abay A, Assey V, Desta T. Ethiopia breaking through with new iodized salt. MI/UNICEF-Ethiopia/GAIN/ICCIDD iodine network/FoH, Ethiopia. In. 2013.

27. Ethiopian public Health Institute. National salt iodization coverage towards Prevention of lodine Deficiency Disorder in Ethiopia. In. 2014.

28. Mesele M, Degu G, Gebrehiwot H. Prevalence and associated factors of goiter among rural children aged 6-12 years old in Northwest Ethiopia, cross-sectional study. BMC Public Health. 2014;14(1):1.

29. World Health Organization, UNICEF, ICCIDD. Assessment of iodine deficiency disorders and monitoring their elimination: a guide for programme managers. In. 2007.

30. FAO. Guidelines for measuring household and individual dietary diversity. In. 2010.

31. Central Statistical Agency [Ethiopia] and ICF International. Addis Ababa, Ethiopia and Calverton, Maryland, USA: Central Statistical Agency and ICF International. In. Ethiopia Demographic and Health Survey 2011. 2012.

32. Wang $Y$, Zhang Z, Ge $P$, Wang $Y$, Wang $S$. lodine deficiency disorders after a decade of universal salt iodization in a severe iodine deficiency region in China. Indian J Med Res. 2009;130(4):413.

33. Kapil U, Pandey RM, Prakash S, Kabra M, Sareen N, Bhadoria AS. Assessment of iodine deficiency in school age children in Nainital District, Uttarakhand State. Asia Pac J Clin Nutr. 2014;23(2):278.

34. Shinde M, Joshi A, Naik G, Trivedi A. Prevalence of goiter and the status of iodized salt among the primary school children of a rural district in central India. Community Med. 2015;6(2):51-5.

35. Sadou H, Dandano IG, Alma MM, Daouda H. lodine Deficiency Disorders After Sixteen Years of Universal Dietary Salt lodization in a Severe lodine Deficiency Village in Niger. Open Nutr J. 2014;8:8-12.

36. Gorstein J, Sullivan K, Parvanta I, Begin F. Indicators and methods for crosssectional surveys of vitamin and mineral status of populations. Atlanta (GA): Micronutrient Initiative (Ottawa) and the Centers for Disease Control; 2007.

37. Biswas AB, Das DK, Chakraborty I, Biswas AK, Sharma PK, Biswas R. Goiter prevalence, urinary iodine, and salt iodization level in sub-Himalayan Darjeeling district of West Bengal, India. Indian J Public Health. 2014; 58(2):129.

38. FLEURY Y, MELLE GV, WORINGER V, GAILLARD RC, PORTMANN L. SeXDependent Variations and Timing of Thyroid Growth during Puberty. J Clin Endocrinol Metab. 2001;86:750-4.

39. Beyene M, Worku AG, Wassie MM. Dietary diversity, meal frequency and associated factors among infant and young children in Northwest Ethiopia: a cross-sectional study. BMC Public Health. 2015;15(1):1.

40. Gebriel TW, Assegid S, Assefa H. Cross-sectional Survey of Goiter Prevalence and Household Salt lodization Levels in Assosa Town, Beni Shangul-Gumuz Region, West Ethiopia. J Preg Child Health. 2014;1:119.
41. Steyn NP, Nel J, Labadarios D, Maunder EMW, Kruger HS. Which dietary diversity indicator is best to assess micronutrient adequacy in children 1 to 9 ? ? Nutrition. 2014;30(1):55-60.

42. Arimond M, Wiesmann D, Becquey E, Carriquiry A, Daniels MC, Deitchler M, Fanou-Fogny N, Joseph ML, Kennedy G, Martin-Prevel Y. Simple food group diversity indicators predict micronutrient adequacy of women's diets in 5 diverse, resource-poor settings. J Nutr. 2010;140(11):2059S-69S.

43. Kebede DL, Adinew YM. Predictors of Goiter among School Children in Southwest Ethiopia: Case-Control Study. J Nutr Food Sci. 2015;5(3):1.

44. Kumar S, Berkman LF. Association of Inadequately lodized Salt Use With Underweight Among Young Children in India. Asia Pac J Public Health. 2015;27(2):185-94

45. Lisboa HRK, Gross JL. Ultrasonographic determination of goiter prevalence in southern Brazilian schoolchildren. Braz J Med Biol Res. 2002;35(10):1147-52.

46. Mardani M, Gholaami F, Rezapour P, Ebrahimzadeh F. The Prevalence of Endemic Goiter and Its Relationship to Urine lodine in Primary School Age Children in Khoramabad. J Health Sci Surveil Syst. 2015;3(2):71-5.

47. Habyarimana JB. Determinants of Household Food Insecurity in Developing Countries Evidences From a Probit Model for the Case of Rural Households in Rwanda. Sustain Agric Res. 2015;4(2):78-91.

48. Aburto N, Abudou M, Candeias V, Wu T. Effect and safety of salt iodization to prevent iodine deficiency disorders: a systematic review with metaanalyses. In: WHO eLibrary of Evidence for Nutrition Actions (eLENA). Geneva: World Health Organization; 2014.

49. Li M, Eastman CJ. The changing epidemiology of iodine deficiency. Nat Rev Endocrinol. 2012:8(7):434-40.

50. Abbag Fl, Abu-Eshy SA, Mahfouz AA, Al-Fifi SA, El-Wadie H, Abdallah SM, Musa MG, Devansan CS, Patel A. lodine-deficiency disorders in the Aseer region, south-western Saudi Arabia: 20 years after the national survey and universal salt iodization. Public Health Nutr. 2015;18(14):2523-9.

\section{Submit your next manuscript to BioMed Central and we will help you at every step:}

- We accept pre-submission inquiries

- Our selector tool helps you to find the most relevant journal

- We provide round the clock customer support

- Convenient online submission

- Thorough peer review

- Inclusion in PubMed and all major indexing services

- Maximum visibility for your research

Submit your manuscript at www.biomedcentral.com/submit
Biomed Central 